\title{
Stress-absorbing elements in dental implants
}

\author{
I. P. van Rossen, D.D.S.,* L. H. Braak, Ph.D.,*** \\ C. de Putter, D.D.S., Ph.D., ${ }^{* * *}$ and K. de Groot, Ph.D.**** \\ Free University, ACTA School of Dentistry, Amsterdam; Eindhoven University of Technology, \\ Eindhoven; and State University Leiden, Faculty of Medicine, Leiden, the Netherlands
}

\begin{abstract}
By means of flnite element analysis, calculations were made of the stress-distribution in bone around implants with and without stress-absorbing elements. A freestanding implant and an implant connected with a natural tooth were simulated. For the freestanding implant, it was concluded that variation in the $E$ modulus of the stress-absorbing element had no effect on the stresses in bone. Changing the shape of the stressmabsorbing element had little effect on the stresses in cortical bone. For the implant connected with a natural tooth, it was concluded that a more uniform stress was obtained around the implant with a low E-modulus of the stress-absorbing element. It was also concluded that the bone surrounding the natural tooth showed a decrease in the height of the peak stresses. (J Prosther DENT 1980;64:188-205.)
\end{abstract}

Long-term successful function of a dental implant depends upon the biocompatibility of the implant material and the biofunctionality of the implant system. Biofunctionality is defined as the mechanical and physical properties that enable an implant to perform its function. ${ }^{1}$ Loaded

*Research Associate, Department of Oral Implantology, Free University, ACTA School of Dentistry.

**Associate Professor, Department of Mechanical Engineering, Eindhoven University of Technology.

***Associate Professor, Department of Oral Implantology, Free University, ACTA School of Dentistry.

****Professor, Department of Biomaterials, Free University, ACTA School of Dentistry; Professor, Department of Biomaterials, Section Cell Biology, State University Leiden, Faculty of Medicine.

$10 / 1 / 18290$ permucosal implants may cause resorption of the surrounding bone, which leads to malfunction, loosening, and ultimate failure of the implant. Resorption may be caused by microbial attack, which leads to infection and bone loss. It is also suggested that high stresses may lead to resorption of bone. By changing the mechanical and physical properties of an implant, it should be possible to avoid high stress concentrations.

Two concepts have been developed to distribute stress more uniformly around dental implants. The first concept assumes a construction that is as rigid as possible, whereby the chewing forces are distributed uniformly over all of the implants. ${ }^{2}$ The second concept attempts to (1) reduce the maximum stress by damping the occlusal forces (stressabsorption) using materials analogous with the natural periodontium ${ }^{3,4}$ (Fig. 1), or (2) redistribute the applied

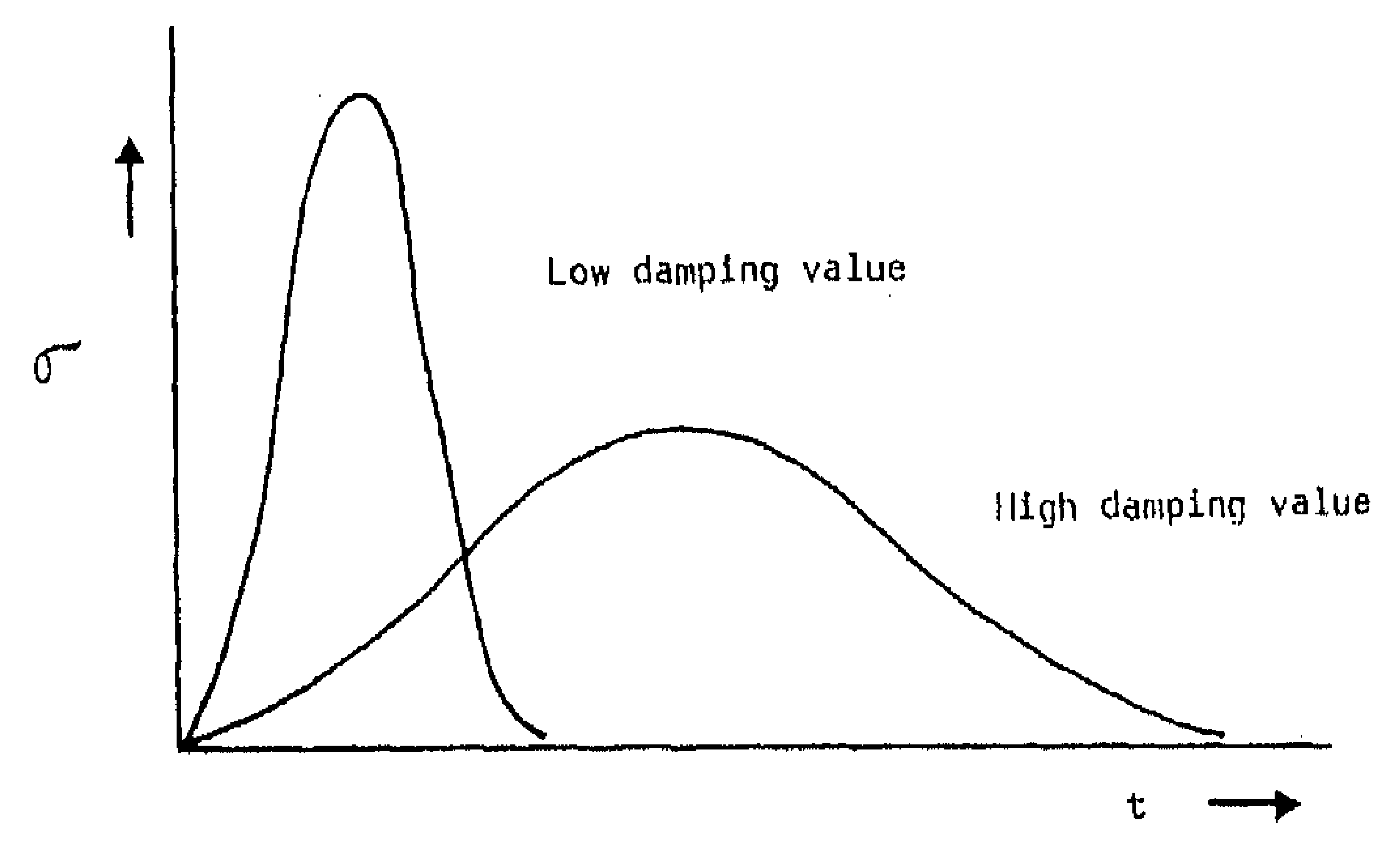

Fig. 1. Stress-absorption is defined as property of material to reduce height of peak stresses in course of time as illustrated in stress versus time graph. Area under functions is same, but maximum stresses differ over varying times. 

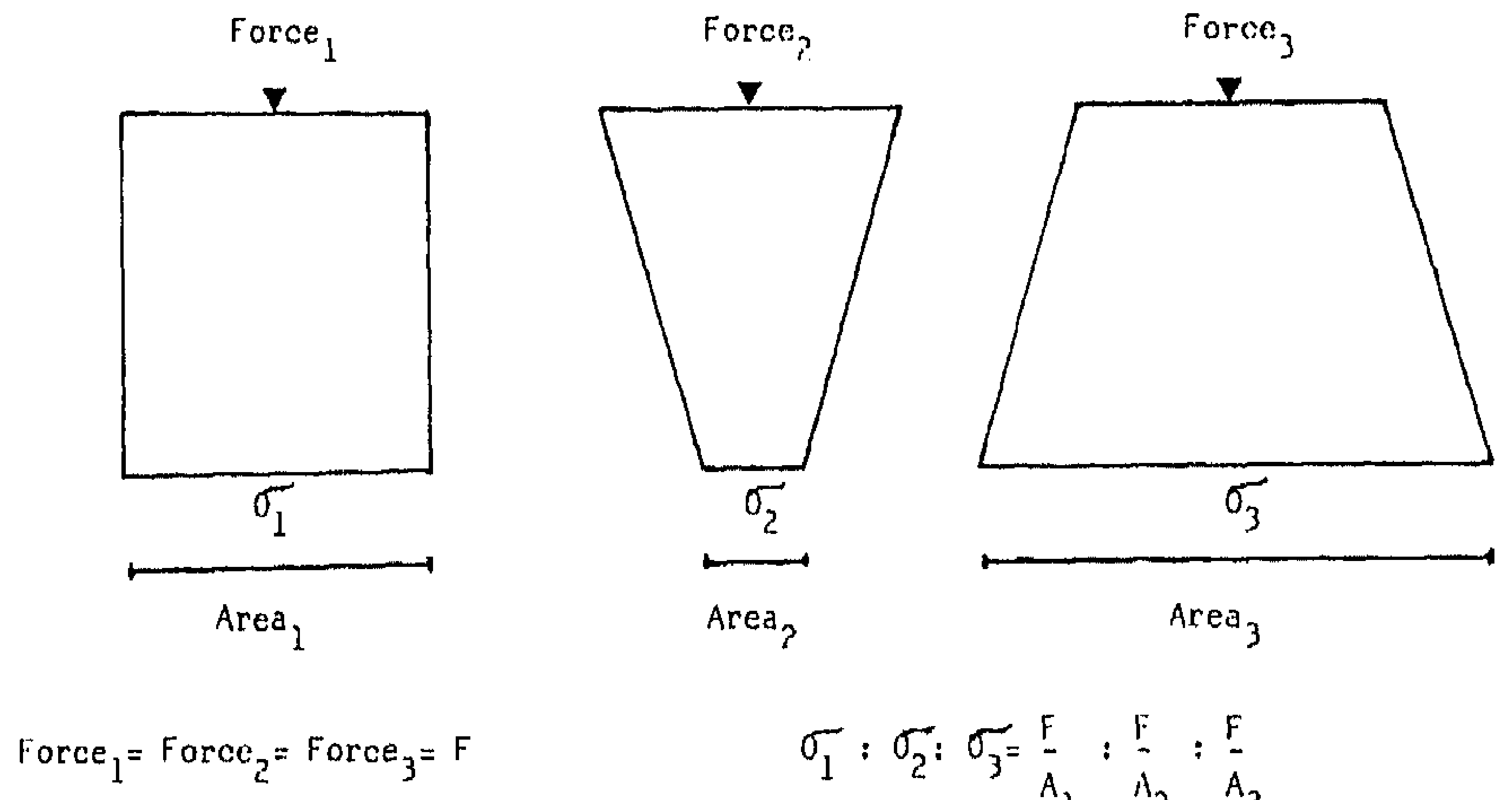

$$
\sigma_{1}: \sigma_{2}: \sigma_{3}=\frac{F}{A_{1}}: \frac{F}{A_{2}}: \frac{F}{A_{3}}
$$

Fig. 2. Stress-distribution is defined as property of structure to distribute or divert forces along stiffest parts of structure. Equal forces result in different stresses when distributed through various-shaped structures.

force (stress-distribution) toward the apex of the implant ${ }^{5}$ (Fig. 2). Each of these concepts is developed differently with respect to prosthetic rehabilitation and desired loading of bone and natural teeth.

Three loading situations are possible with dental implants: (1) loading a freestanding implant, (2) loading an implant connected with a natural tooth, and (3) loading two implants connected with each other. In this study, the first two situations are analyzed to ascertain with finite element analyses which of the concepts mentioned, or which of the combinations of concepts, gives the most equal stress-distribution in bone when using a stress-absorbing element (SAE).

Finite element analysis is a numerical method based on the principle of dividing a structure into a finite number of small elements that are connected with each other at the cornerpoints or nodes. For each element, its mechanical behavior can be written as a function of the displacements of the nodes. These nodes are submitted to certain loading conditions, resulting in a behavior of the model similar to the structure it represents.

In this analysis, FEMSYS, a program that has been developed at the Eindhoven University of Technology ${ }^{6}$ and that has been used for calculations or orthopedic implants, ${ }^{7}$ was used.

\section{MATERIAL AND METHODS}

The two models constructed were (1) an axisymmetric model to simulate a freestanding single implant in vertical load and (2) a model to simulate an implant connected with a natural tooth, also in vertical load. The first model was constructed of axisymmetric elements with three nodes (Figs. 3 and 4). The second model was constructed of threeand four-noded membrane elements (Figs. 5 and 6).
The program used implied several assumptions with regard to the mechanical properties of the simulated structures.

1. Homogeneity: The mechanical properties of a material are thought to be the same in the entire structure.

2. Isotropy: The material properties are the same in all directions.

3. Linear elasticity: The deformation or strain of the structures is proportional to the applied force and independent of the strain rate.

The material properties of the structures are shown in Table I. The values of the E-modulus of cortical and trabecular bone as given in the literature vary; therefore a mean value was used for both types of bone.

A force of 500 newtons was applied to the single implant. A force of 160 newtons was applied to the tooth-connected implant. This force is in agreement with natural toothloading forces during mastication. ${ }^{8,9}$ On each model, two calculations were completed. In the first calculation, the stress-absorbing element was characterized by an E-mod. ulus of $150 \mathrm{MPa}$. In the second calculation, the stress-absorbing element was characterized by an E-modulus of $110,000 \mathrm{MPa}$. The different levels of E-modulus simulated a soft and a rigid material between the suprastructure and the implant.

\section{RESULTS}

\section{Freestanding implant}

The stresses in the cortical bone at the interface with the implant that contained a stress-absorbing element with an E-modulus of $150 \mathrm{MPa}$ varied from 12 to $45.5 \mathrm{MPa}$. The stresses in the trabecular bone, also calculated at the implant interface, varied from 3.3 to $9.8 \mathrm{MPa}$ (Fig. 7). The calculations computed on the implant with a stress-ab- 


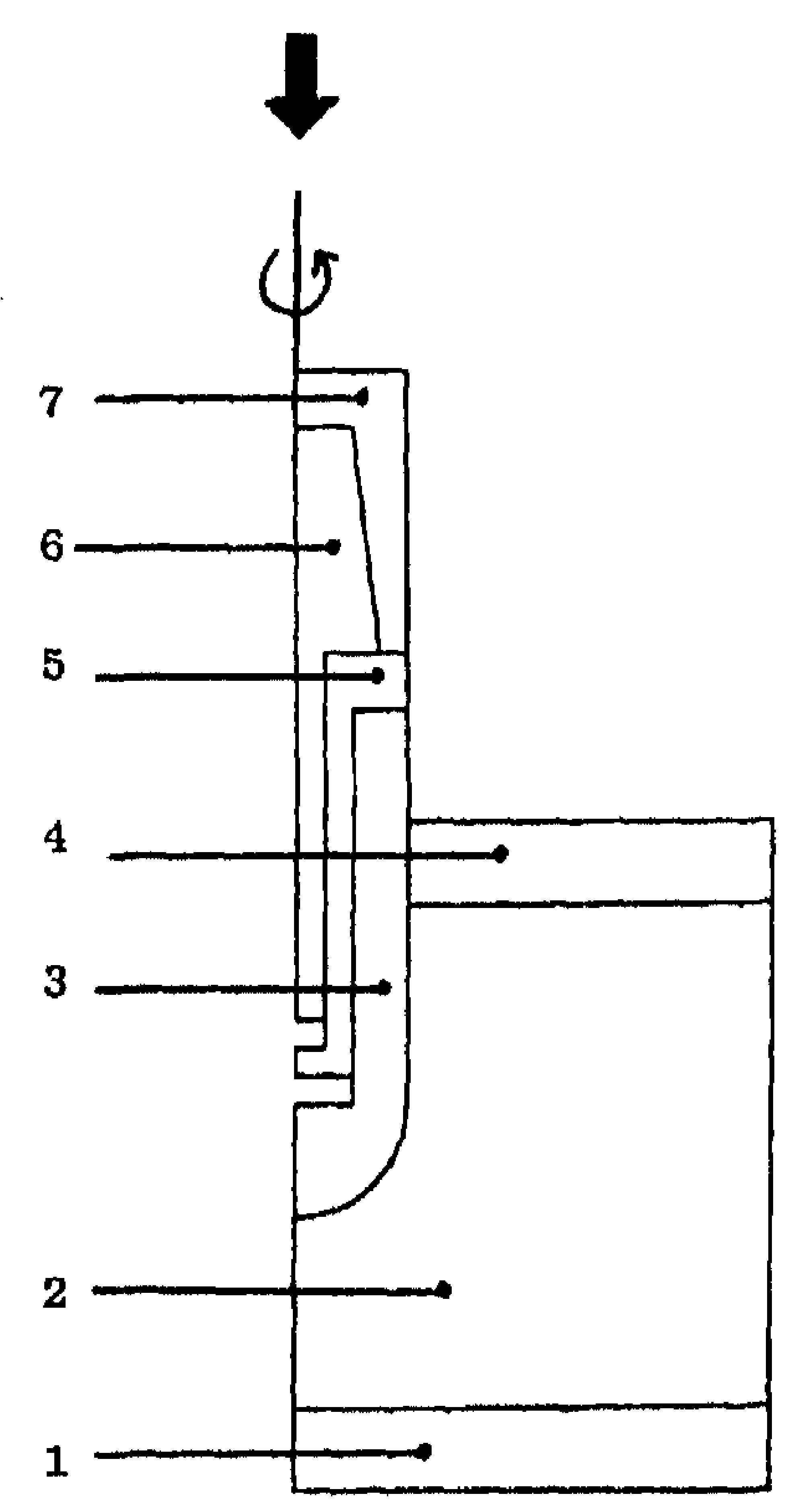

Fig. 3. Finite element model of freestanding implant: 1 , cortical bone; 2 , trabecular bone; 3 , submucosal part of implant; 4, cortical bone; 5 , stress-absorbing element; 6 , post; 7, core. Arrow indicates direction and point of application of force.

Table I. Material properties

\begin{tabular}{lcc}
\hline \multicolumn{1}{c}{ Material } & E-modulus (MPa) & Poisson-ratio \\
\hline Cortical bone & 15,000 & 0.3 \\
Trabecular bone & 1,500 & 0.3 \\
Dentin & 12,000 & 0.3 \\
Periodontal ligament & 2.0 & 0.45 \\
Titanium & 110,000 & 0.35 \\
$\quad$ (submucosal part) & & \\
Post and core & 210,000 & 0.35 \\
Stress-absorbing & 110,000 and 150 & 0.3 \\
$\quad$ element & & \\
\hline
\end{tabular}

sorbing element having a high E-modulus (110,000 $\mathrm{MPa}$ ) produced similar results. Similar findings indicate that redistribution of the applied force in a freestanding implant is not possible by changing the E-modulus of the stressabsorbing element. For this reason, calculations were also completed on single implants with different shapes of the stress-absorbing element.

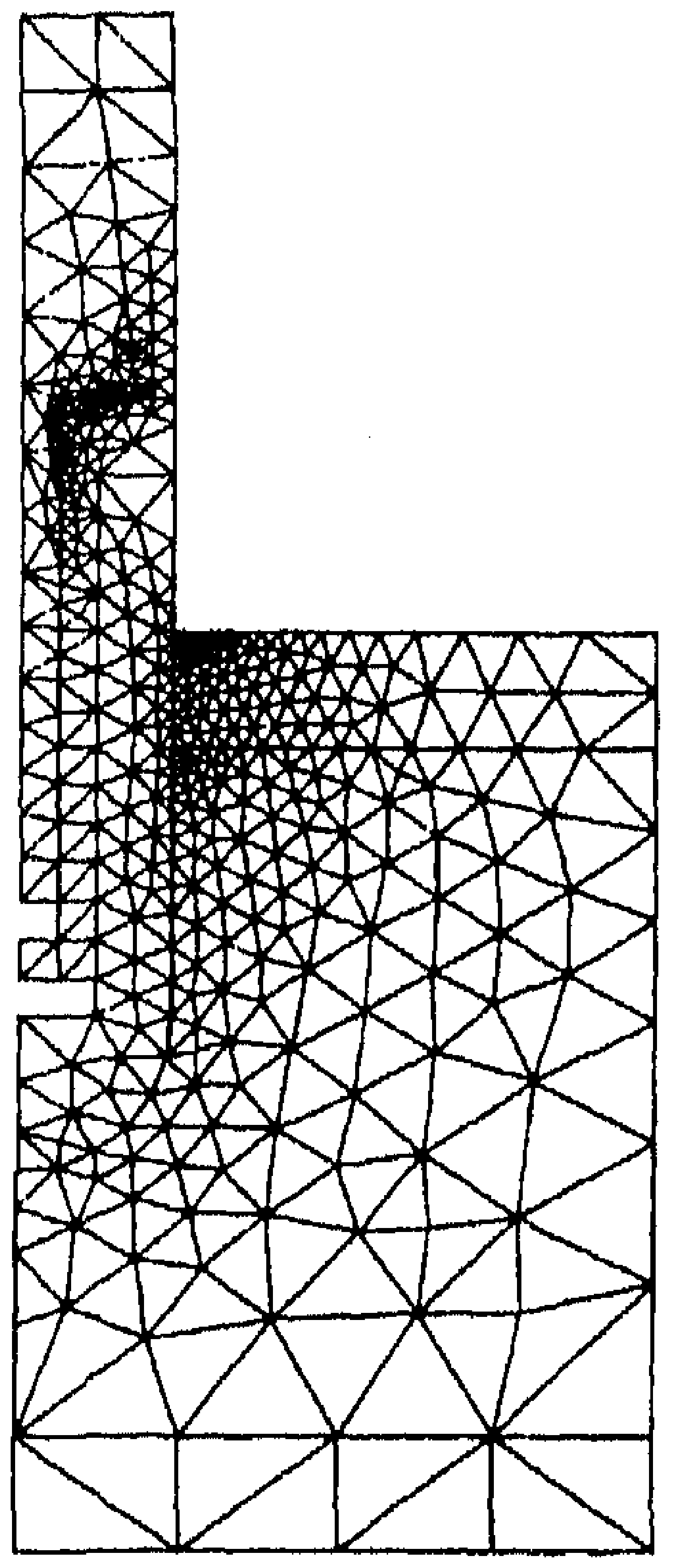

Fig. 4. Mesh of finite element model.

The different shapes of the stress-absorbing element attempted to (1) reduce the stiffness of the implant at the cortical level, (2) decrease the thickness of the metal at the cortical level, and (3) apply the force more apically. These changes resulted in slightly different stresses in the cortical bone around the implant (Fig. 8). Shape No. 4 was a model with a direct contact between post and core and the apical part of the implant when the stress-absorbing element was eliminated. The shape of the stress-absorbing element with the lowest stress ( $42 \mathrm{MPa}$ ) was used in the model of the tooth-connected implant.

\section{Tooth-connected implant}

In the model of the tooth-connected implant, the stresses in the cortical bone (Fig. 9) and in the trabecular bone (Fig. 10) were considered. In Fig. 9, the linepiece C-D-E, along which stresses are given in the trabecular bone, is put in the graphic for reasons of clarity, A stress-absorbing element with a high E-modulus resulted in stresses in the cortical bone (Fig. 9) that varied from 3.7 to $11.9 \mathrm{MPa}$ between points $B$ and $C$. Between points $E$ and $F$, the stresses varied from 13.4 to 51.1 MPa. The difference in stress between points $B$ and $F$ was $39.2 \mathrm{MPa}$ and between points $C$ and $E$, 21.3 MPa. In the trabecular bone (Fig. 10) the stresses around the implant varied between 0.24 and $7.7 \mathrm{MPa}$. Between points $\mathrm{D}$ and $\mathrm{E}$, the stress increased from 2.7 to 4.4 $\mathrm{MPa}$. 


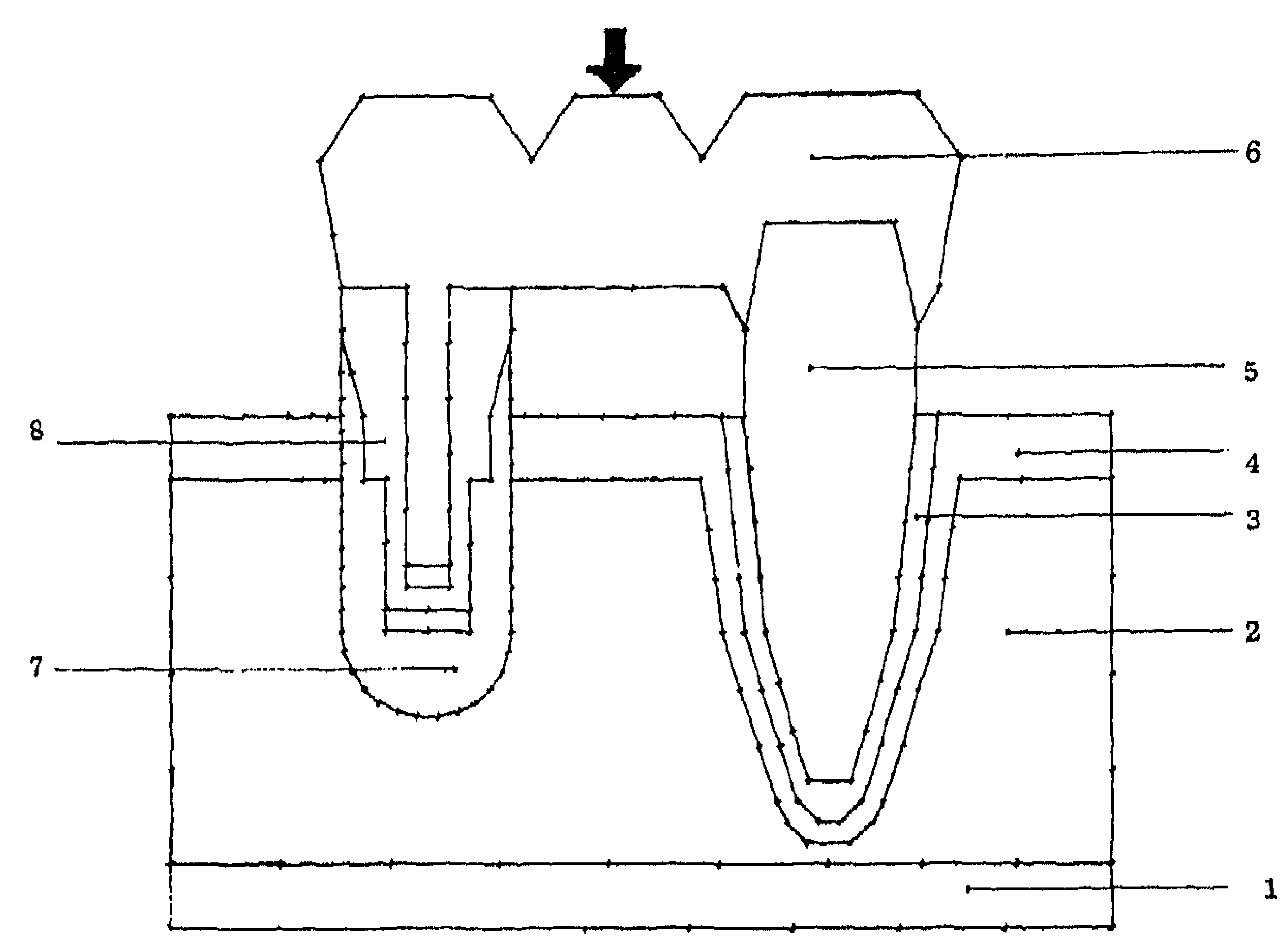

Fig. 5. Finite element model of tooth-connected implant.

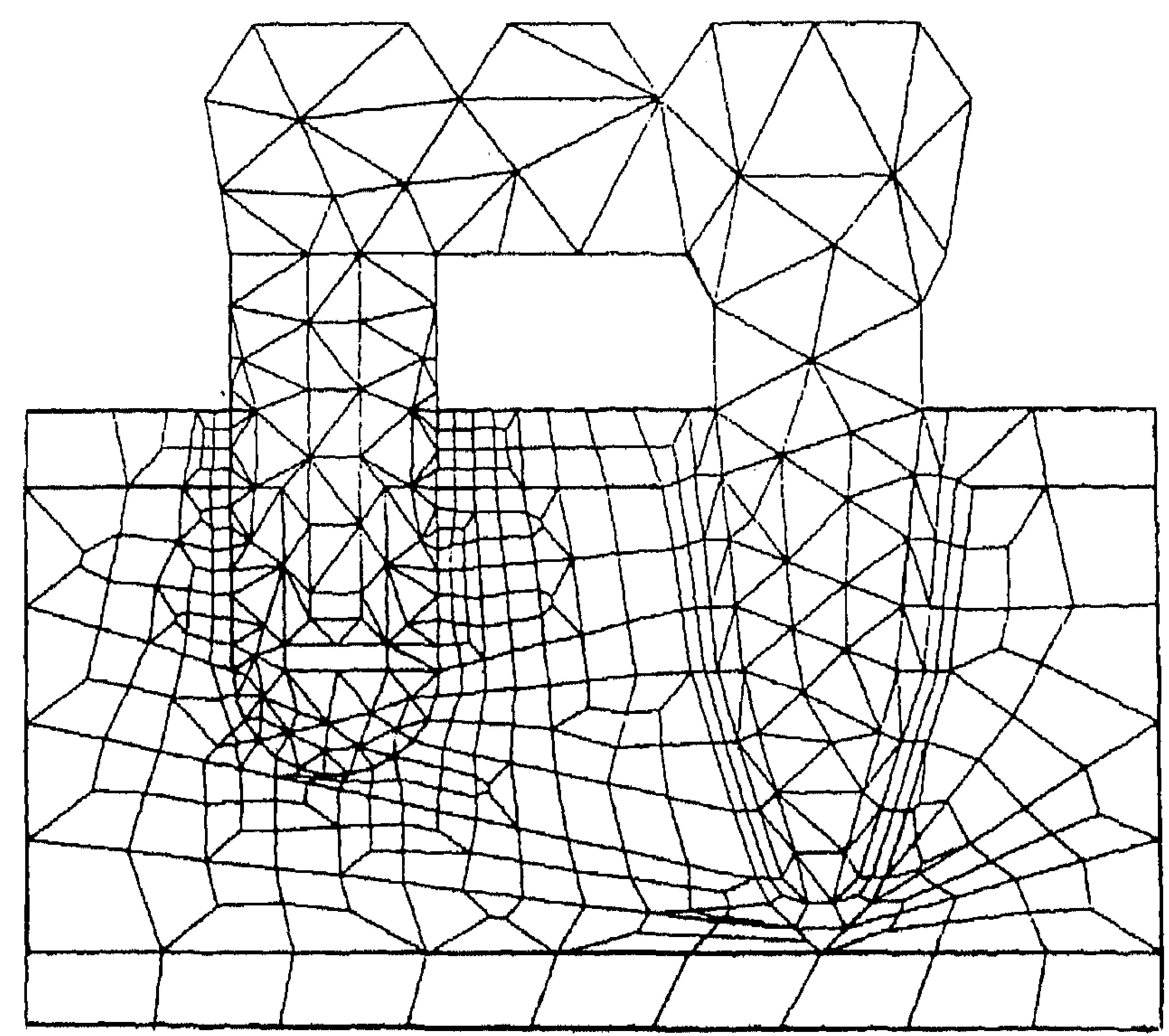

Fig. 6. Mesh of finite element model of tooth-connected implant.

When using a stress-absorbing element with a low E-modulus, the stresses in cortical bone (Fig. 9) varied from 4.6 to $22.6 \mathrm{MPa}$ between points $\mathrm{B}$ and $\mathrm{C}$. Between points $\mathrm{E}$ and $\mathrm{F}$, the stresses ranged from $9.8 \mathrm{MPa}$ to $46.3 \mathrm{MPa}$. The difference in stress between the symmetric points $B$ and $F$ and points $\mathrm{C}$ and $\mathrm{E}$ were, respectively, $23.7 \mathrm{MPa}$ and 9.3 MPa. In the trabecular bone (Fig. 10), the stresses varied from 0.6 to $5.2 \mathrm{MPa}$ between points $\mathrm{B}$ and $\mathrm{D}$. As was also 


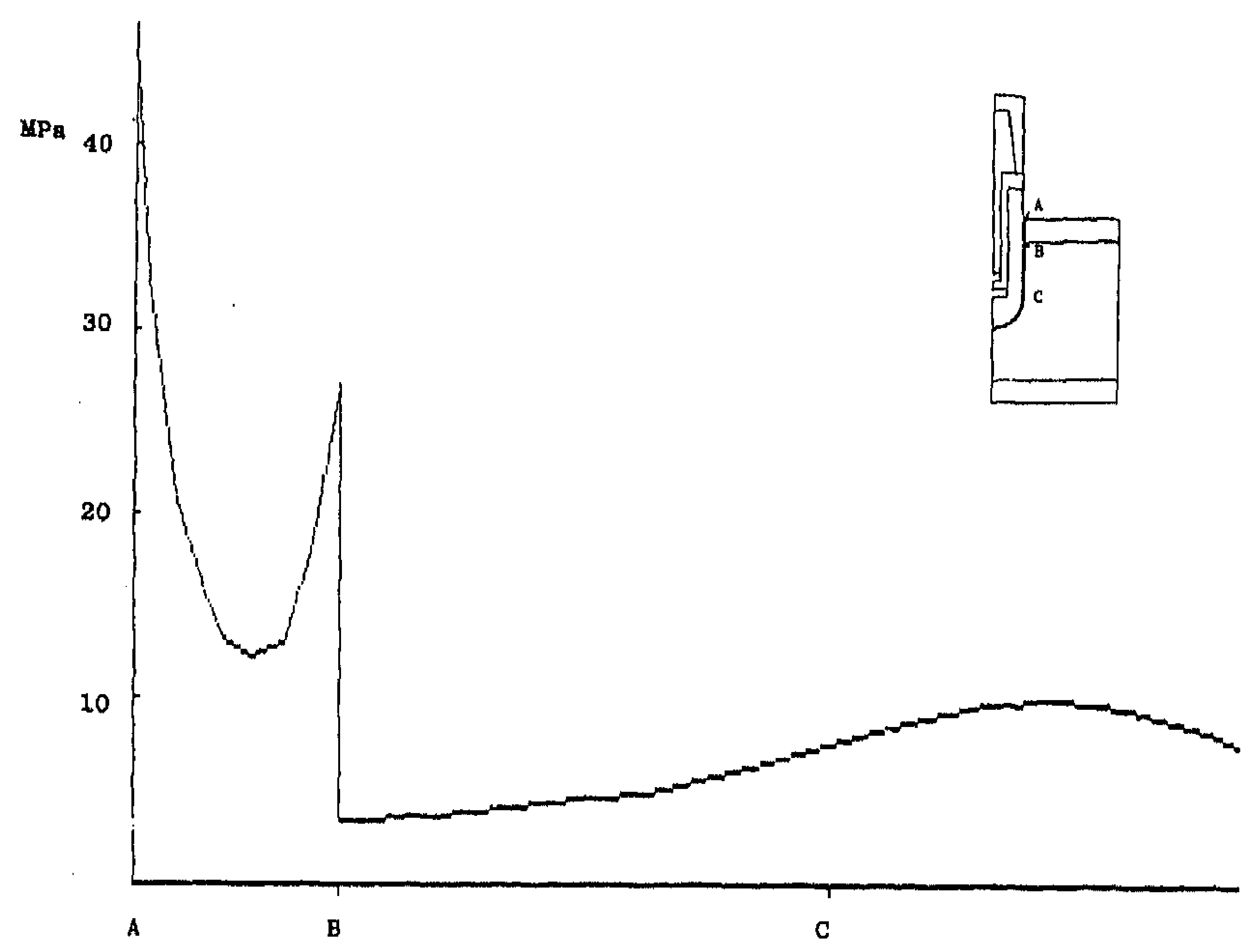

Fig. 7. Calculated von Mises stresses along implant-bone interface.

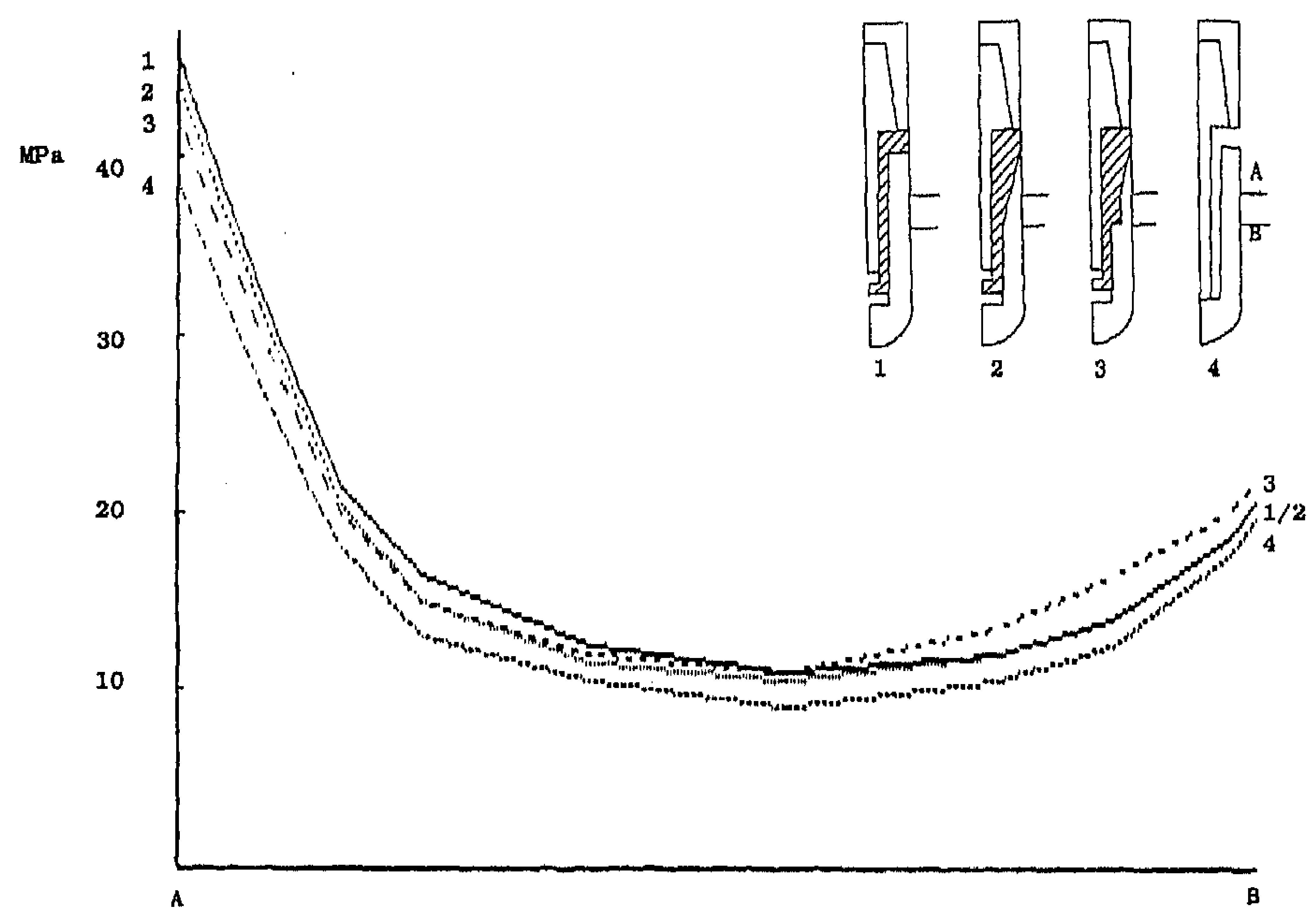

Fig. 8. Calculated von Mises stresses in cortical bone (linepiece AB) with different shapes of stress-absorbing element.

seen in the model with a high $\mathrm{E}$-modulus of the stress-absorbing element, the stress increased between points $D$ and E from 1.5 to $3.1 \mathrm{MPa}$ in this model.

The effect of the stress-absorbing element on the loading of the natural tooth was a decrease of the height of the peak stresses from 44.5 to $35.4 \mathrm{MPa}$ and from 29.2 to 15.9 $\mathrm{MPa}$ (Fig. 9, between points $\mathrm{G}$ and $\mathrm{H}$ ).

\section{DISCUSSION}

Whether stress-absorbing elements are functional in an implant system has been an issue of interest in oral implantology. 2, 4, 5, 10 Theoretically, their function can be twofold. Initially, stress-absorbing elements can act as a damping structure reducing the height of the peak stresses under dynamic loading conditions. Secondly, the stress- 


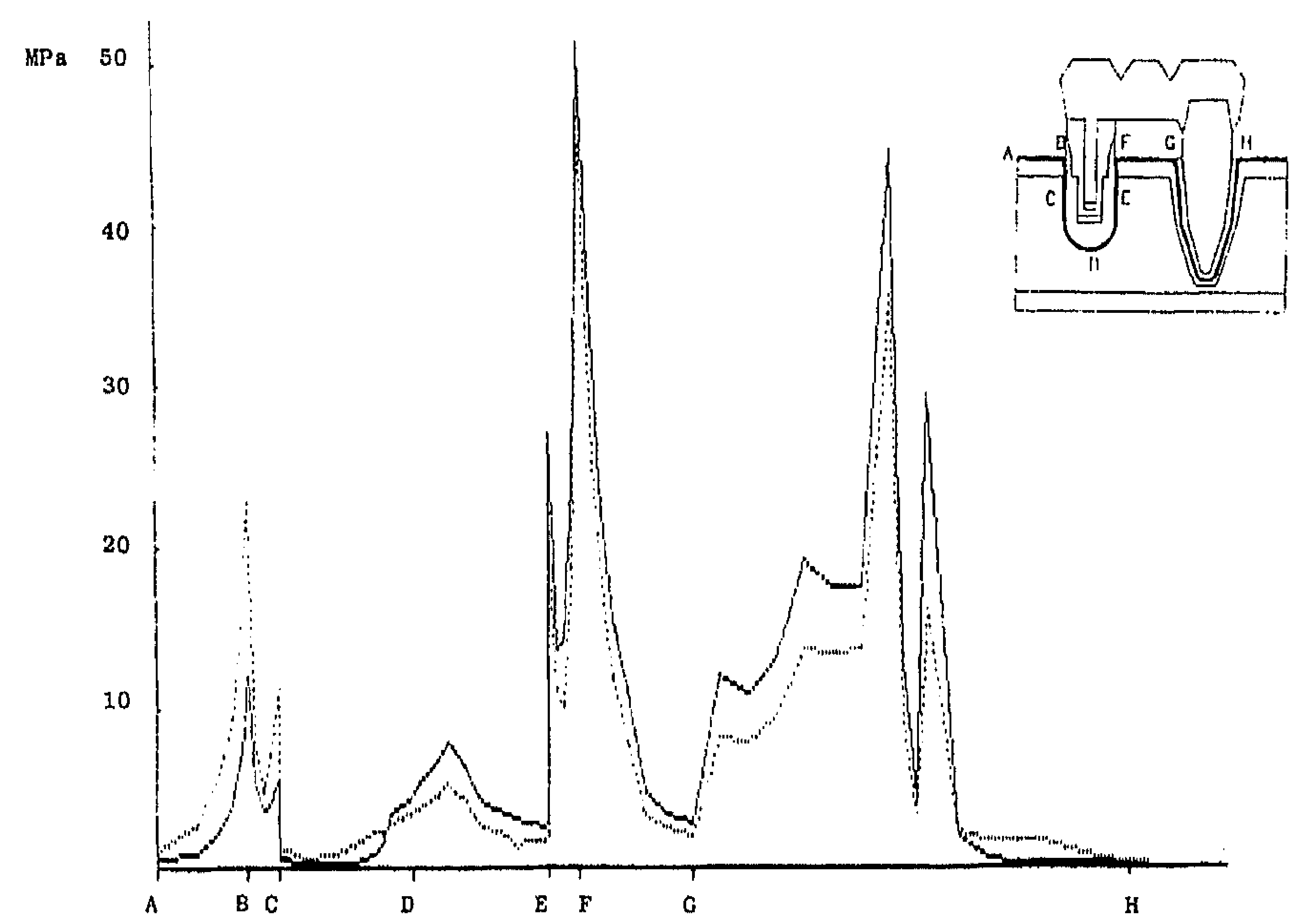

Fig. 9. Stresses along line A-B-C-D-E-F-G-H, which is located mainly in cortical bone. $(\ldots, 150 \mathrm{MP}$ $110,000 \mathrm{MPa}$.)

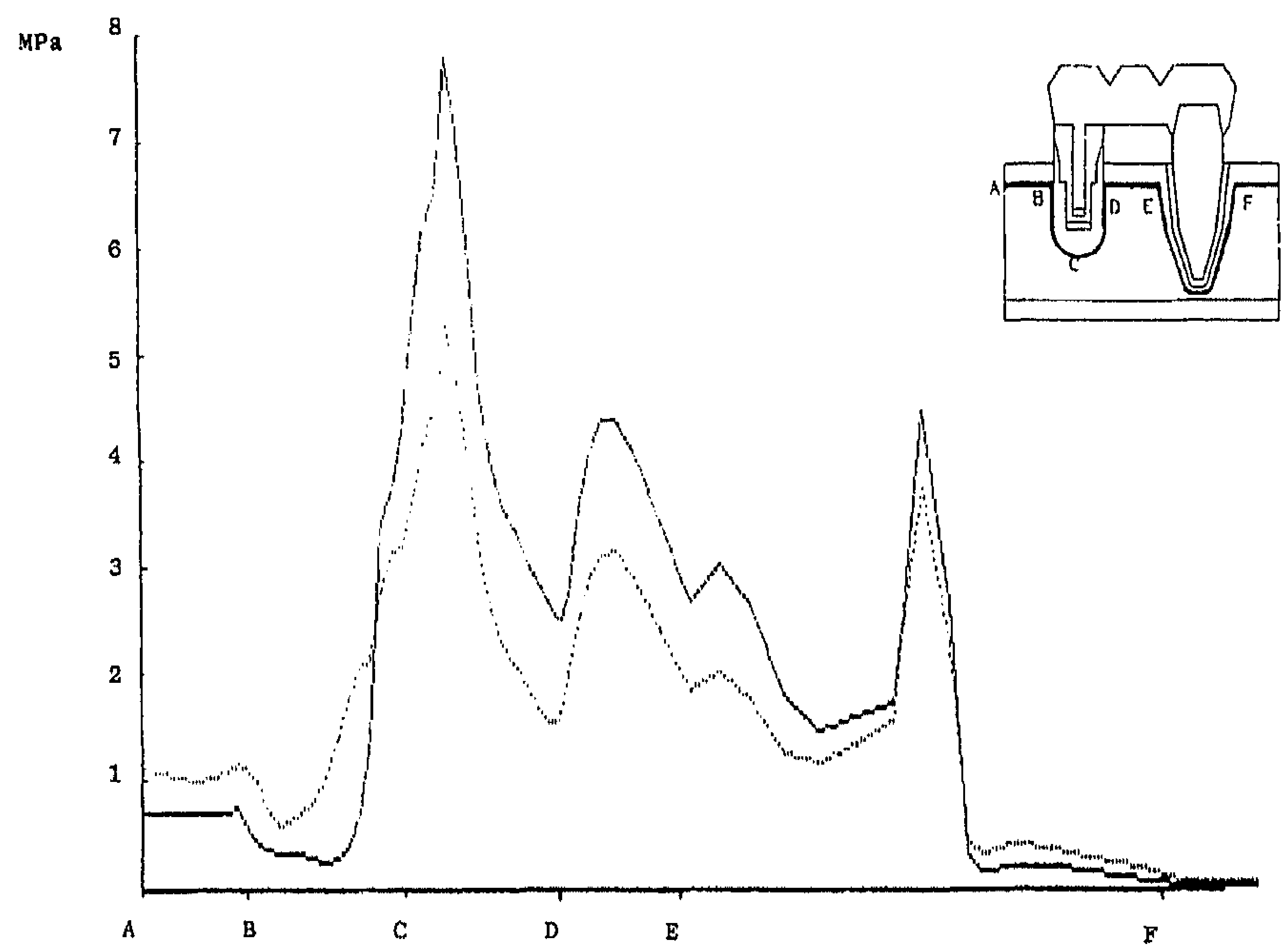

Fig. 10. Stresses along line A-B-C-D-E-F, which is located completely in trabecular bone. $(\ldots, 150 \mathrm{MPa}$ 110,000 MPa.)

absorbing elements are thought to act as a stress-distributor where forces can be diverted to other locations in the bone or around the implant. Stress-distribution in the bone can be slightly manipulated, although the total force remains constant. Whether stress-absorption or stress-distribution plays the major role depends on the construction of the implant system and on the material properties.
In this study, calculations were made with finite element analysis (FEA), a research method used in oral implantology to predict stress and strain situations in bone. ${ }^{11-14}$ The finite element program used in this investigation has several limitations with respect to the simulation of the ma. terial properties of the structures. The program assumes that the structures are homogeneous, linear-elastic, and 


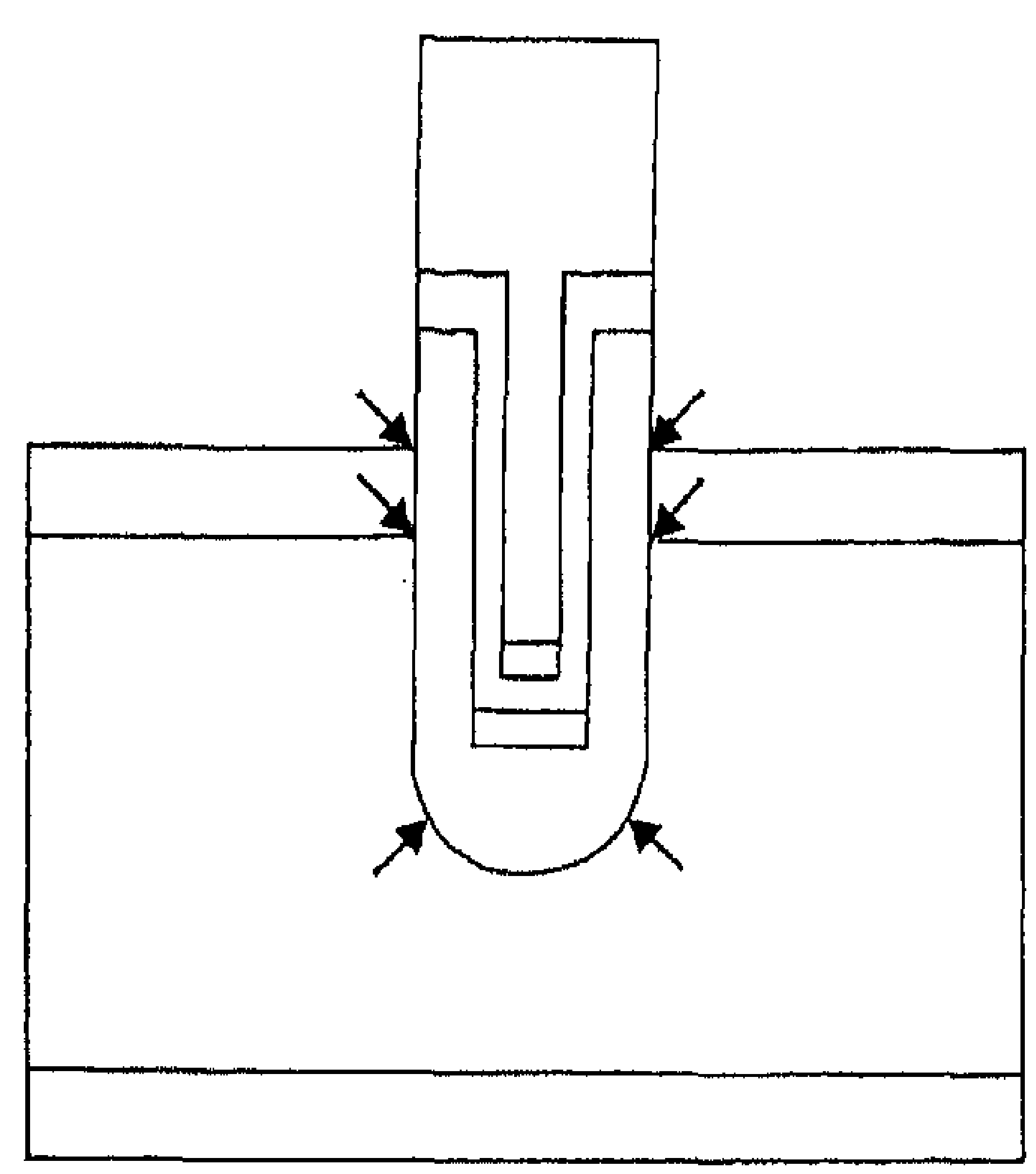

Fig. 11. Locations where largest changes in bone density are to be expected in freestanding implant according to finite element program.

isotropic, while bone and the periodontal ligament are nonhomogeneous, viscoelastic, and anisotropic structures. ${ }^{15-19}$ These differences mean that the calculated values may not be taken as absolute values but, at most, as relative values of stresses in structures under static loading. Nevertheless, FEA provides some insight into the stressdistributions in the structures mentioned.

The results show that changing the E-modulus of the stress-absorbing element in a freestanding implant does not affect the stress-distribution around the implant during static loading. This finding could mean that if there is any measurable biologic effect of the stress-absorbing element on the bone, it is related to the damping properties of the stress-absorbing element during dynamic loading.

When different shapes of the stress-absorbing element were used, only small stress decreases were calculated in the cortical bone around freestanding implants. Perhaps larger decreases would be seen if the E-modulus of the implant itself were decreased. ${ }^{20}$

In cortical bones, the decrease of the stress-difference between points $\mathrm{B}$ and $\mathrm{F}$ from $39.2 \mathrm{MPa}$ to $23.7 \mathrm{MPa}$ shows that changing the E-modulus of the stress-absorbing element in a construction where the implant is connected with a natural tooth has an effect on the stress-distribution in the bone. A soft stress-absorbing element causes the stress to be more uniform. More uniform stress around the implant could be explained because displacement of the bridge is more a translation than a rotation, which is the case in a rigid implant system. There would be an almost total vertical loading of the implant if the E-modulus of the stress-absorbing element were the same as the periodontal ligament. On the basis of these calculations, the largest

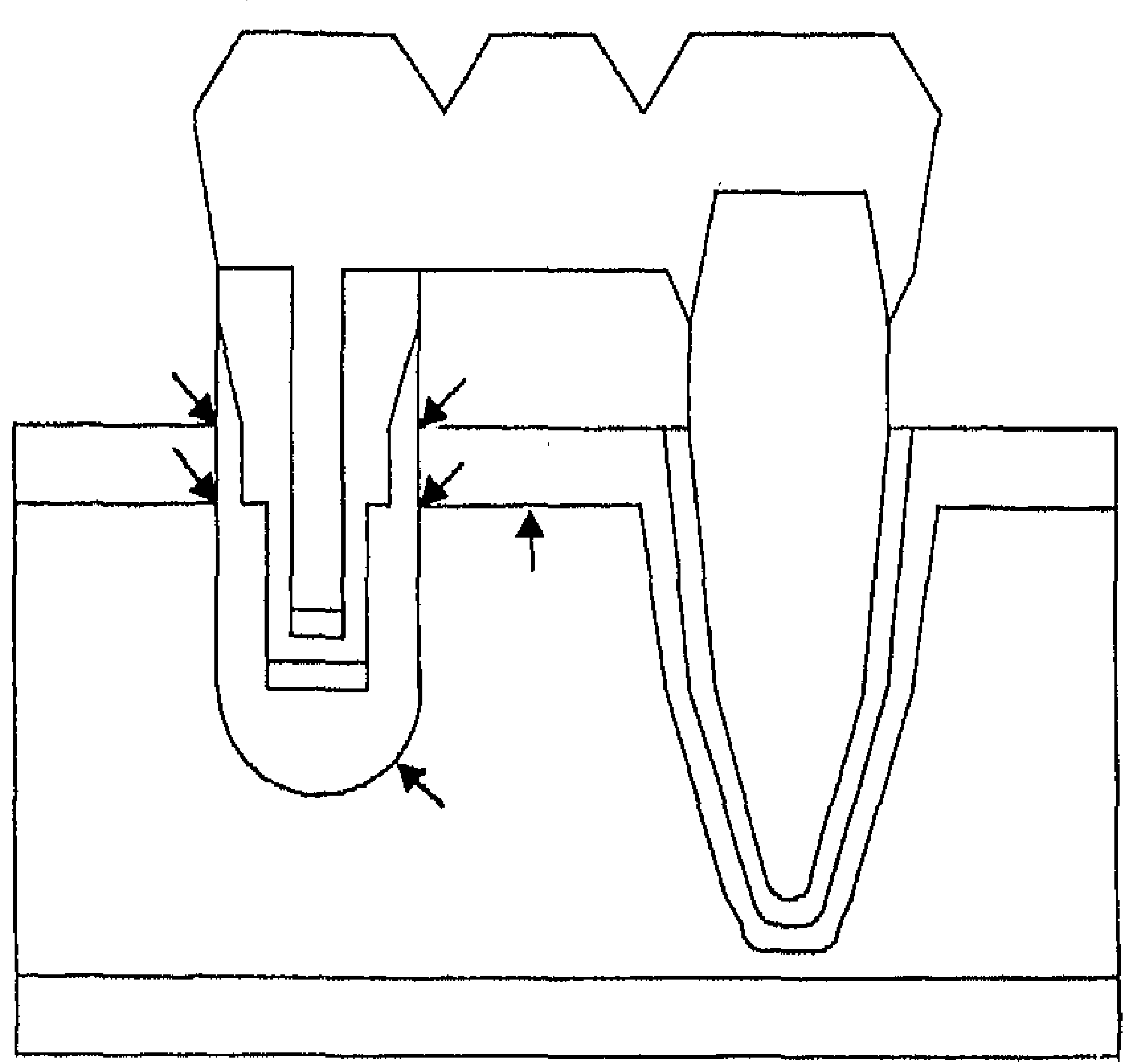

Fig. 12. Locations around implant where largest changes in bone density are to be expected in tooth-connected implant.

stresses in the structure were defined. It is our expectation that in these places the largest changes in bone density will also be seen (Figs. 11 and 12).

\section{CONCLUSIONS}

The results of this study suggest that:

1. A stress-absorbing element (SAE) in a freestanding implant may function as a damping element but not as a stress-distributor.

2. A stress-absorbing element in an implant that is connected with a natural tooth causes the bone around the implant to be loaded more uniformly.

3. Using a stress-absorbing element with a low E-modulus in an implant connected with a tooth decreases the height of the peak stresses in the cortical bone surrounding the natural tooth.

4. Changing the shape of a stress-absorbing element in a freestanding implant produces only small changes in stress-distributions in the cortical bone.

5. If there is a biologic effect when using a stressabsorbing element in an implant connected with a natural tooth, the largest relative effects are to be expected in trabecular bone.

\section{SUMMARY}

By means of finite element analysis, calculations were made of the stress-distribution in bone around implants with and without stress-absorbing elements. A freestanding implant and an implant connected with a natural tooth were simulated.

For the freestanding implant, it was concluded that variation in the E-modulus of the stress-absorbing element 
had no effect on the stresses in bone. Changing the shape of the stress-absorbing element had little effect on the stresses in cortical bone.

For the implant connected with a natural tooth, it was concluded that a more uniform stress was obtained around the implant with a low E-modulus of the stress-absorbing element. It was also concluded that the bone surrounding the natural tooth showed a decrease in the height of the peak stresses.

\section{REFERENCES}

1. Williams DF, Implants in dental and maxillofacial surgery. Biomaterials $1981 ; 2: 133-46$.

2. Skalak RS. Biomechanical considerations in osseointegrated prostheses. J PROSTHET DENT 1983;49:843-8.

9. Kooh WLK. Die Zweiphagige enossalo Implantation von Intramobilen Zylinderimplantaten -IMZ- (I + II + III). Die Quintegsenz 1976;27:23 $31 ; 21-7 ; 39-46$.

4. Ney Th. Zur kinematik von implantaten und naturlichen zahnen. Dtsch Zahnaratl Z 1986;42:1039-44.

5. Siegele $D$, Soltesz U. Implantate mit intramobilen einsetzen als bruck enpfeiler, ein vergleich der im knochen erzeugten spannungsverteilun. gen. Z Zahnarztl Implantol 1986;II:117-24.

6. Peters FJ. FEMSYS; systeem voor op de eindige elementenmethode gebsgeerde berekeningen. Internal report, Eindhoven University of Tochnology, 1976.

7. Huiskes HWJ. Some fundamental aspects of human joint replacement. Thesis, Eindhoven University of Technology, 1979.

8. Anderson DJ. Measurements of stress in mastication; I + II. J Dent Res 1956;35:664-70.

9. Anderson DJ. Measurements of stress in mastication; II. J Dent Res 1956;35:671-3.

10. Kirsch A, Ackermann KL, Das IMZ-implantat-system. Dtsch Zahnarztl Z 1986;42:1134-44
11. Borchers L, Reichart $P$. Three-dimensional stress distribution around a dental implant at different stages of interface development. J Dent Res 1983;62:156-9.

12. Weinstein AM, Klawitter JJ, Cook SD. Implant-bone interface characteristics of bioglass dental implants. J Biomed Mat Res 1980;14:23-9.

13. Widera GEO, Tesk JA, Privitzer E. Interaction effects among cortical bone, cancellous bone, and periodontal membrane of natural teeth and implants. J Biomed Res Symposium 1976;7:611-23.

14. Wright KWJ, Yettram AL. Reactive force distributions for teeth when loaded singly and when used as fixed partial denture abutraents. $J$ PROSTHET DENT 1979;42:411-6.

15. Bonfield W. Elasticity and viscoelasticity of cortical bone. In: Hastings GW, Ducheyne P, eds. Natural and living bioraaterials. Boca Raton, Fla.: CRC Pross, 1984:43-60.

16. Katz JL, Meunier A. The elastic anisotropy of bone. J Biomechanic8 $1987 ; 20 ; 1063-70$.

17. Evans FG, Mechanical properties of bone. Springfield, Ill: Charles C Thomas, 1975 .

18. Richter EJ. Die bedeutung der versuchsbedingungen im wissenschaftlichen expeximent, dargestellt am beispiel der zahnbeweglichkeit. Dtsch Zahnarztl Z 1985;40:404-9.

19. de Boer A. Mechanical behaviour of the periodontal ligament; measurements and numerical analyses. Academical thesis, State University of Utrecht, 1987

20. Cook SD, Klawitter JJ, Weinstein AM. The influınce of implant elastic modulus on the stress distribution around LTI sarbon and aluminum oxide dental implantr. J Biomed Mater Res 1981;15;879-87.

Reprint requests to:

DR. I. P. VAN ROSSEN

DEPARTMENT OF ORAL IMPLANTOLOGY, ACTA

SCHOOL OF DENTIBTRY

FreE UNIVERSITY

LOUWESWEG 1

1066EA AMSTERDAM 